\title{
Intracervical block compared with intramuscular sedation for dilatation and curettage
}

\author{
Poornima C*, Seetha Panicker
}

Department of Obstetrics and Gynecology, PSG Institute of Medical Sciences \& Research, Coimbatore-641004, Tamilnadu, India

Received: 9 January 2014

Accepted: 2 February 2014

*Correspondence:

Dr. Poornima C,

E-mail: poornimatolstoy@rediffmail.com

(C) 2014 Poornima $\mathrm{C}$ et al. This is an open-access article distributed under the terms of the Creative Commons Attribution Non-Commercial License, which permits unrestricted non-commercial use, distribution, and reproduction in any medium, provided the original work is properly cited.

\begin{abstract}
Background: Dilatation and curettage is one of the most commonly performed office based gynecological procedures. As this procedure is associated with pain, is often done using conscious sedation. The purpose of this study is to estimate the efficacy of intracervical block (ICB) versus intramuscular (IM) sedation on pain experienced during this procedure.

Methods: This was a prospective study comparing ICB with IM sedation in women undergoing dilatation and curettage (D\&C) for abnormal uterine bleeding (AUB). Both groups received $400 \mathrm{mcg}$ of misoprostol vaginally $1 \mathrm{hr}$ before the procedure and pain was assessed during cervical dilatation, uterine wall scraping and 1 hour after the procedure by using a $10 \mathrm{~cm}$ visual analogue scale (VAS).

Results: For the sixty women who underwent D\&C there was statistically significant difference $(\mathrm{p}<0.001)$ in pain scale were observed between ICB and IM sedation during endometrial scraping and post procedure. Mean recovery time was $1.02 \mathrm{hrs}$ in ICB group where as in IM group it was $3.78 \mathrm{hrs}$.

Conclusion: Pain relief in ICB administration is more effective than IM sedation during D\&C procedure. The recovery period in intracervical block is faster when compared to IM sedation. ICB is easier technique of administration, and cost effective.
\end{abstract}

Keywords: Intracervical block, Intramuscular sedation, Pain

\section{INTRODUCTION}

D\&C refers to the dilatation of the cervix and surgical removal of part of the lining of the uterus and/or contents of the uterus by scraping and scooping (curettage). It has both diagnostic as well as therapeutic value in AUB patients as well as a rarely used method of first trimester abortion. ${ }^{1,2}$

As this procedure is associated with pain and discomfort, this can be performed under local anesthesia, conscious sedation (or) general anesthesia (GA). As GA is associated with anesthetic complications, need for hospital stay \& high cost, only few clinics use GA. ${ }^{3}$ It is important to identify best method of analgesia. The various approaches for local uterine anesthesia require an understanding of uterine anatomy. Cervix receives its innervations from S24 largely via the uterosacral ligaments while the corpus is innervated by $\mathrm{T} 10$ to $\mathrm{L} 1$, distributed with the uterine and ovarian vasculature, more cephalad in the broad ligament $\&$ above. As a result, procedural anesthesia using local anesthetic agents must consider both pathways. ${ }^{4}$ Two methods of local anesthetic administration include paracervical and intracervical block. ICB acts as an infiltrative anesthetic by distending the tissues, causing mechanical disruption of neural impulses. 


\section{METHODS}

This prospective study included 60 women with AUB attending the department of obstetrics and gynecology. Among them 30 received ICB and another 30 received IM sedation. Pregnant women and those allergic to lidocaine were considered as exclusion criteria. All the women received $400 \mathrm{mcg}$ of misoprostol vaginally $1 \mathrm{hr}$ before the procedure for cervical softening. Those women who subjected for ICB were tested for lidocaine allergy prior the procedure. The ICB was administered using 20 gauge needle in order to overcome increased resistance to injection caused by cervical stroma. $10 \mathrm{ml}$ of $1 \%$ lidocaine is injected into cervical stroma at 2, 5, $7 \& 110$ ' clock position ( $2.5 \mathrm{ml}$ in each site) $1-2 \mathrm{~cm}$ deep and parallel to the long axis of the cervix as shown in figure $1 . \mathrm{We}$ selected these sites to avoid injury to the vessels. For IM sedation group, we used $30 \mathrm{mg}$ of Pentazocine and $12.5 \mathrm{mg}$ of Promethazine $1 \mathrm{hr}$ before the procedure. The primary outcome of pain was assessed using a $10-\mathrm{cm}$ $\mathrm{VAS}^{11}$ at three points, during cervical dilatation, endometrial scraping and 1 hour following procedure. The recovery time following procedure was recorded. Patients were observed for complications due to the procedure like bleeding, perforation of the uterus and also problems related to the anesthesia.

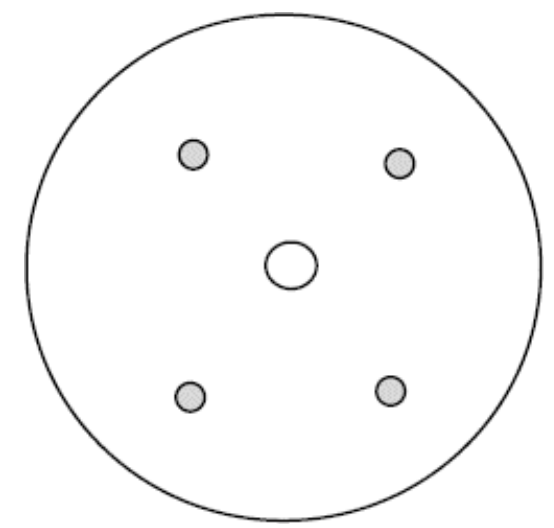

Figure 1: Intracervical block injection sites.

\section{RESULTS}

A total of 60 women were included in this study and divided into 2 groups (30 cases in each group). Both groups received vaginal misoprostol 1 hour prior procedure for cervical softening. Primary outcome measures analyzed were pain during cervical dilatation, endometrial scraping, and 1 hour following procedure and secondary outcome measures we recorded were recovery period and complications.

The mean pain score of cervical dilatation was 0.8 in the ICB group and 1.1 in the IM sedation group, while the score for endometrial scraping was 3.2 in the ICB group and 5.1 in IM sedation group. One hour post procedure pain score for ICB group was 1.1 and 3.1 in the IM sedation group (Table 1).
Table 1: Mean pain score.

\begin{tabular}{|llll|}
\hline & Analgesia & $\begin{array}{l}\text { Number } \\
\text { of patients }\end{array}$ & $\begin{array}{l}\text { Mean pain } \\
\text { score }\end{array}$ \\
\hline $\begin{array}{l}\text { Cervical } \\
\text { dilatation }\end{array}$ & ICB & 30 & 0.866 \\
\cline { 2 - 4 } & IM & 30 & 1.133 \\
\hline $\begin{array}{l}\text { Endometrial } \\
\text { scraping }\end{array}$ & ICB & 30 & 3.200 \\
\cline { 2 - 4 } & IM & 30 & 5.133 \\
\hline $\begin{array}{l}\text { Post- } \\
\text { procedure }\end{array}$ & ICB & 30 & 1.133 \\
\cline { 2 - 4 } & IM & 30 & 3.133 \\
\hline
\end{tabular}

There was a statistically significant difference in pain scale between ICB and IM sedation group during endometrial scraping and post procedure (Figure $2 \& 3$ ) $(\mathrm{p}<0.001)$. But there is no difference in pain during cervical dilatation (Figure 1).

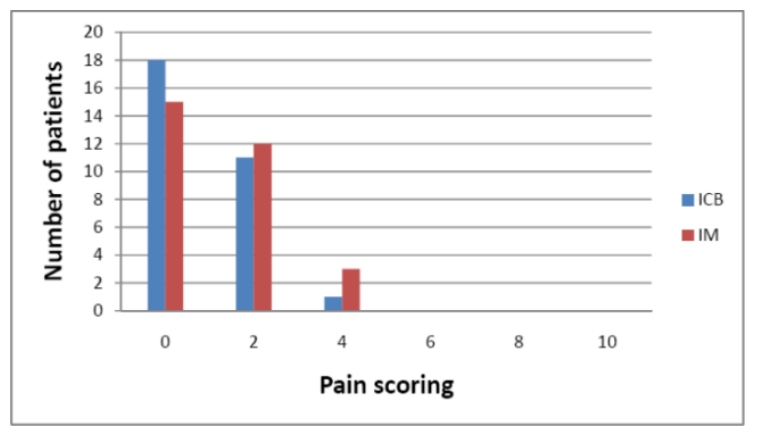

Figure 1: Pain during cervical dilatation.

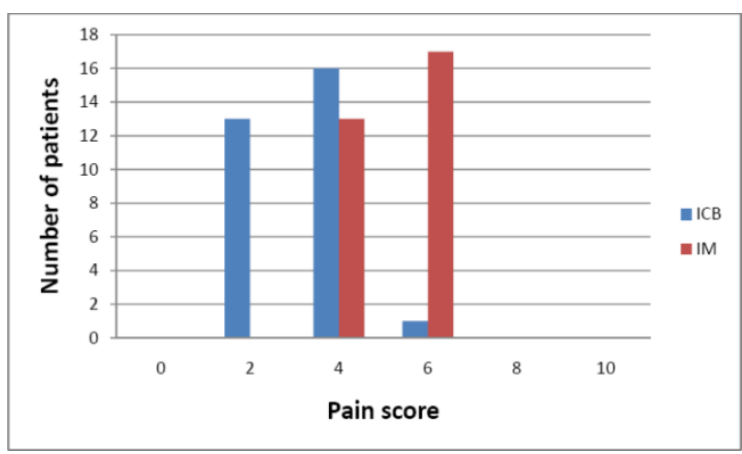

Figure 2: Pain during endometrial scraping.

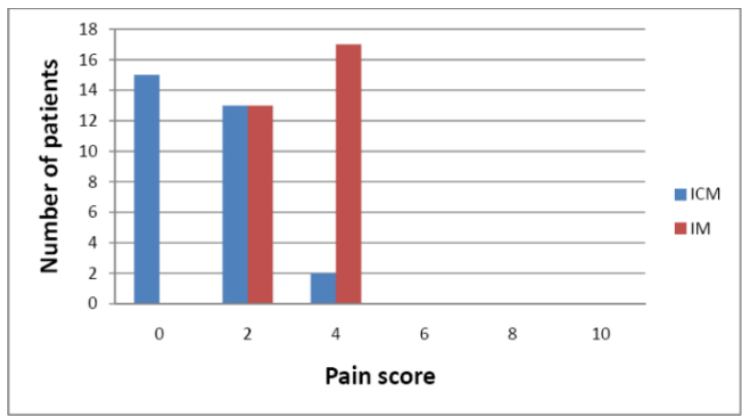

Figure 3: Pain 1 hour following procedure. 
Table 2: Mean recovery time in both groups.

\begin{tabular}{|llll|}
\hline & $\begin{array}{l}\text { Analgesia } \\
\text { code }\end{array}$ & $\begin{array}{l}\text { Number of } \\
\text { patients }\end{array}$ & $\begin{array}{l}\text { Mean } \\
\text { duration } \\
\text { time }\end{array}$ \\
\hline \multirow{2}{*}{ Recovery } & ICB & 30 & $1.02 \mathrm{hrs}$ \\
\cline { 2 - 4 } & IM & 30 & $3.78 \mathrm{hrs}$ \\
\hline
\end{tabular}

The recovery in ICB group is faster when compared to IM sedation group which is statistically significant $(\mathrm{p}<0.001)$. The mean duration of recovery in the IM sedation group is 3.78 hours (Table 2).

The only side effects in IM sedation group was nausea $(5 / 30)$ and vomiting $(2 / 30)$, where as in ICB group side effects were almost nil.

\section{DISCUSSION}

$\mathrm{D} \& \mathrm{C}$ is one of the most commonly performed procedures in gynecology. It is used to diagnose and treat many conditions that affect the uterus, such as abnormal bleeding. During this procedure, pain is associated mainly during cervical dilatation and endometrial scraping. This procedure can be done by two methods of local administration of anesthesia which includes paracervical block and intracervical block. Jennifer et al., 2009, studied 132 women who underwent suction curettage with conscious sedation; there was no clinically significant difference in pain relief between paracervical and intracervical block. They found ICB is an easier technique to perform and to teach. ${ }^{5}$ ICB can be offered to other gynecological procedures like HSG, hysteroscopy, ${ }^{7}$ IUD insertion and removal of lost IUD, and during LEEP procedure.

Chauhan MB et al., in their study (pain relief during hysterosalpingography: role of intracervical block) observed reduction of pain from placement of tenaculm till end of procedure (T3-T6) with intracervical block $(p<0.05)$. Pain remained at a statistically lower level during the most painful steps i.e. traction of the cervix (VAS: $2.080 .49 \mathrm{~cm}, 95 \%$ CI 1.18-2.98 VS. $4.21 .15 \mathrm{~cm}$, 95\% CI 3.3-5.1, $\mathrm{p}=0.001)$ and with the insertion of dye (VAS: 2.640 .49 , 95\% CI $1.7-3.5$ vs. $5.121 .45 .95 \%$ CI 4.3-6.0, $\mathrm{p}=0.001$ ) in the study group as compared to control group. ${ }^{6}$

Hepburn S. in his study (Method of local anesthesia for IUD insertion) used intracervical block for all IUD insertions. The described technique is simple, low cost, requires no special equipment. ${ }^{8}$

Thumwadee Tangsirinatthana et al., concluded intracervical injection significantly reduced pain during, and 15 minutes after, for LEEP procedure, more than cervical spray did, without serious adverse effects. ${ }^{9}$
In our study with the usage of vaginal misoprostol prior the procedure, no patient in the both groups complained of intolerable pain during cervical dilatation. Smitakant et al., study showed a significant difference between the study group $(7.7 \pm 1.7 \mathrm{~mm})$ and the control group $(4.5 \pm 1.8 \mathrm{~mm})$ in terms of pre procedural cervical width and the number of women requiring additional dilatation (7/25 versus 22/25), and hence, the time required for dilatation is less with usage of vaginal misoprostol $(4.7 \pm 8$ seconds vs. $20.6 \pm 9.3$ seconds). This study concluded that vaginal misoprostol as a cervical priming agent in postmenopausal women appears to be safe, effective, and in expensive, with mild side effects. ${ }^{10}$

\section{CONCLUSION}

During D\&C pain relief associated with ICB administration was more effective than with IM sedation $(\mathrm{P}<0.001)$. The recovery in ICB was faster when compared to IM sedation. Post procedure complications with ICB are almost negligible if correctly performed. It is also an easier technique of administration and cost effective.

According to the results of this study, ICB is more effective than IM sedation for $\mathrm{D} \& \mathrm{C}$ procedure.

\section{ACKNOWLEDGEMENTS}

We gratefully acknowledge the help of our department colleagues and nursing staffs of labour ward.

\section{Abbreviations}

D\&C - dilatation and curettage

ICB - intracervical block

IM - intramuscular

AUB - abnormal uterine bleeding

VAS - visual analogue scale

GA - general anesthesia

HSG - hysterosalpingography

IUD - intrauterine device

LEEP - loop electro excision procedure

Funding: None

Conflict of interest: None declared

Ethical approval: Obtained

\section{REFERENCES}

1. Hayden Merrill. Dilation and curettage (D\&C) for dysfunctional uterine bleeding. Healthwise (200602-22) Dilation and sharp curettage (D\&C) for abortion. Women's Health.

2. Nissl. Dilation and curettage (D\&C) for bleeding during menopause. Healthwise Jan (2005-01-18).

3. Griems DA, Schulz KF, et al. Local versus GA: which is safer for performing sution curettage abortions. Am J Obstet Gynecol 1979;135:1030-5. 
4. Muro MG. Uterine anesthesia in the office setting. December 3, 2008.

5. Jennifer L. Mankowski, Jessica Kingston, et al. Paracervical compared with Intracervical lidocaine for suction curettage. Obstet Gynecol 2009;113;1052-7.

6. Chauhan $\mathrm{MB}$, et al. Pain relief during hysterosalpingography: role of intracervical block. Archives of Gynecology and obstetrics.2013;287:155-9.

7. Helena O, Flynn, Lavern L, Murphy Galfy Ahmad, Andrew J.S. Watson. Pain relief in outpatient hysteroscopy. Eur J Obstet Gynecol Reprod Biol 2011;154:9-15.

8. Hepburn S. Method of local anesthesia for IUD insertion. Contracept Deliv Syst. 1980 Oct;(4):3717.
9. Thumvadu Tangsirinatthana, et al. Journal of Gynecologic Surgery, October 2013;29(5):241-244. doi ; 10.1089/gyn. 2013.0017.

10. Shyama Prasad Sana, et al. Vaginal misoprostol for cervical priming before gynecological procedures on non pregnant women. International Journal of Health sciences. 2007 July;(12):185-93.

11. Warden V, Hurley AC, Volicer L. Development and psychometric evaluation of the pain assessment in advanced dementia (PAINAD) scale. Journal of the American Medical Directors Association 2003;4:915.

DOI: $10.5455 / 2320-1770 . i j r \operatorname{cog} 20140329$

Cite this article as: Poornima C, Panicker S. Intracervical block compared with intramuscular sedation for dilatation and curettage. Int J Reprod Contracept Obstet Gynecol 2014;3:149-52. 